\title{
Cost-effectiveness of primary offer of IVF vs. primary offer of IUI followed by IVF (for IUI failures) in couples with unexplained or mild male factor subfertility
}

\author{
Nora Pashayan*1, Georgios Lyratzopoulos² and Raj Mathur ${ }^{3}$
}

Address: ${ }^{1}$ Department of Public Health and Primary Care, Institute of Public Health, University Forvie Site, Robinson Way, Cambridge CB2 2SR, UK, ${ }^{2}$ Norfolk Suffolk and Cambridgeshire Strategic Health Authority, Victoria House, Capital Park, Fulbourn, Cambridge, CB1 5XB, UK and ${ }^{3}$ Cambridge University Teaching Hospitals Foundation Trust, Hills Road, Cambridge, CB2 2QQ, UK

Email: Nora Pashayan* - np275@medschl.cam.ac.uk; Georgios Lyratzopoulos - Georgios.Lyratzopoulos@nscsha.nhs.uk; Raj Mathur - r.mathur@addenbrookes.nhs.uk

* Corresponding author

Published: 23 June 2006

BMC Health Services Research 2006, 6:80 doi:10.1 186/1472-6963-6-80

This article is available from: http://www.biomedcentral.com/1472-6963/6/80

(C) 2006 Pashayan et al; licensee BioMed Central Ltd.

This is an Open Access article distributed under the terms of the Creative Commons Attribution License (http://creativecommons.org/licenses/by/2.0), which permits unrestricted use, distribution, and reproduction in any medium, provided the original work is properly cited.
Received: 12 December 2005

Accepted: 23 June 2006

\begin{abstract}
Background: In unexplained and mild male factor subfertility, both intrauterine insemination (IUI) and in-vitro fertilisation (IVF) are indicated as first line treatments. Because the success rate of IUI is low, many couples failing IUI subsequently require IVF treatment. In practice, it is therefore important to examine the comparative outcomes (live birth-producing pregnancy), costs, and costeffectiveness of primary offer of IVF, compared with primary offer of IUI followed by IVF for couples failing IUI.
\end{abstract}

Methods: Mathematical modelling was used to estimate comparative clinical and cost effectiveness of either primary offer of one full IVF cycle (including frozen cycles when applicable) or "IUI + IVF" (defined as primary IUI followed by IVF for IUI failures) to a hypothetical cohort of subfertile couples who are eligible for both treatment strategies. Data used in calculations were derived from the published peer-reviewed literature as well as activity data of local infertility units.

Results: Cost-effectiveness ratios for IVF, "unstimulated-IUI (U-IUI) + IVF", and "stimulated IUI (SIUI) + IVF" were $£|2,600, £| 3,100$ and $£ \mid 5,100$ per live birth-producing pregnancy respectively. For a hypothetical cohort of 100 couples with unexplained or mild male factor subfertility, compared with primary offer of IVF, 6 cycles of "U-IUI + IVF" or of "S-IUI + IVF" would cost an additional $£ \mid 74,200$ and $£ 438,000$, representing an opportunity cost of 54 and 136 additional IVF cycles and 14 to 35 live birth-producing pregnancies respectively.

Conclusion: For couples with unexplained and mild male factor subfertility, primary offer of a full IVF cycle is less costly and more cost-effective than providing IUI (of any modality) followed by IVF.

\section{Background}

In any health care system, cost-effective commissioning of health care in order to maximise population health outcomes with the minimum possible resource use, is an important consideration. The UK National Institute for Clinical Excellence (NICE) [1] recommends offer of up to six cycles of Unstimulated Intrauterine Insemination (UIUI) for couples with unexplained or mild male factor 


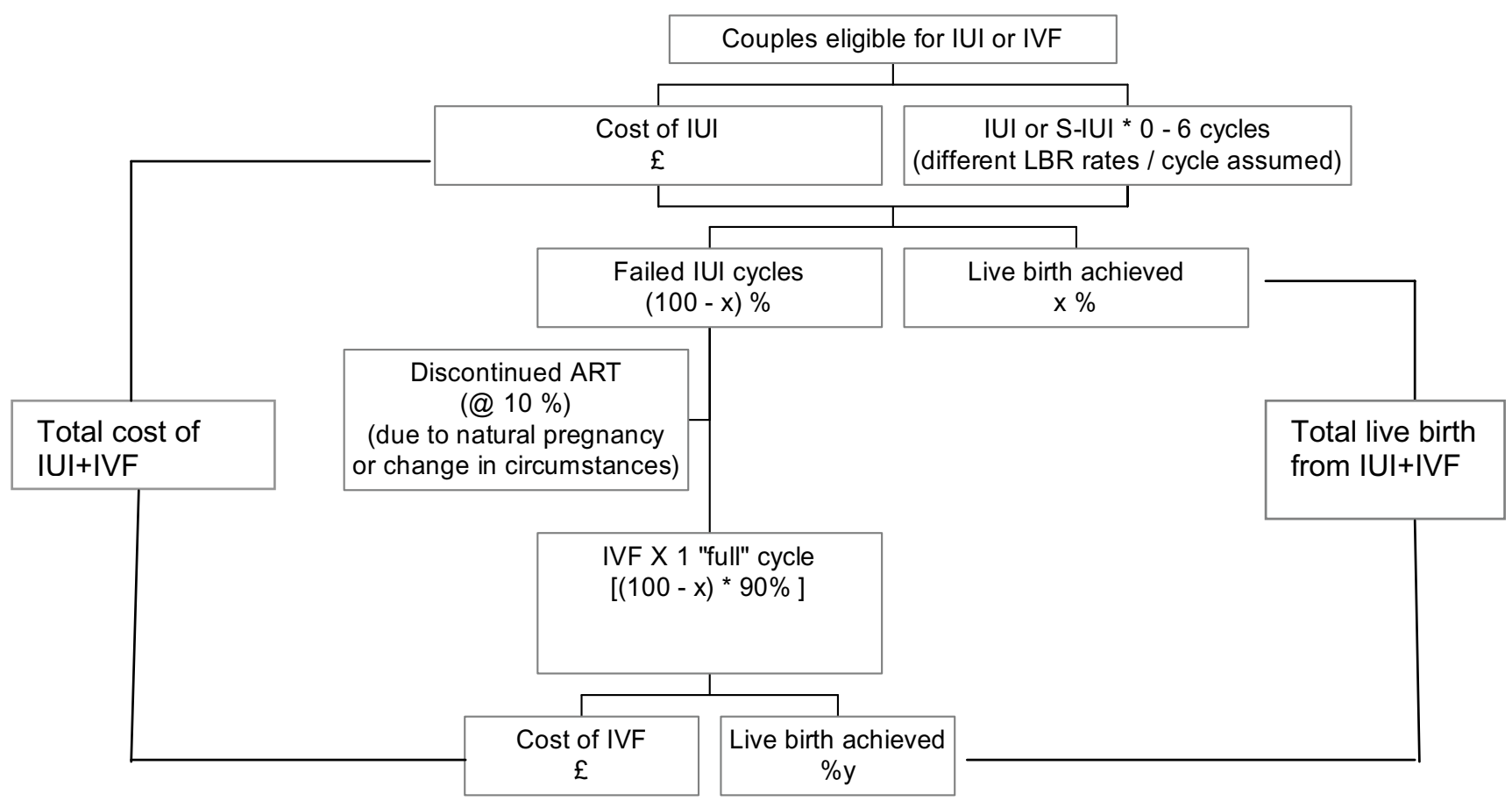

Figure I

The structure of the generic model. U-IUI: Unstimulated IUI S-IUI: Gonadotrophin stimulated IUI C-IUI: Clomifene stimulated IUI ART: Assisted reproductive technique LBR: Live birth rate

subfertility. Supplementary cost calculation guidance suggested overall savings to the NHS from a "switch" of activity from Stimulated IUI (S-IUI) to U-IUI, which was also recommended [2]. These calculations however were based on 'head-to-head' comparisons between S-IUI and U-IUI and completely ignored the cost implications of the fact that many couples who fail IUI will subsequently require in-vitro fertilisation (IVF) treatment.

Even if some health care interventions may have a relatively low cost per treatment session, they could be less cost-effective compared to alternative treatments with a higher cost per treatment session, but also better clinical effectiveness. It is therefore legitimate to examine critically whether funding for IUI allows better management of current demand, or whether it increases activity and overall associated healthcare expenditure for those couples who are eligible for both treatment strategies [3]. We therefore constructed a mathematical model to evaluate the costeffectiveness of provision of IUI followed by IVF compared to primary offer of IVF for patients who according to NICE are eligible for both treatment strategies.

\section{Methods}

\section{Model construction}

The structure of the generic model is presented in Figure 1 . The model emulates the clinical experience of a hypo- thetical cohort of 100 couples with unexplained or mild male factor subfertility by different treatment strategy, including, when applicable, the transition from one to another treatment stage or strategy. The outcome examined was live birth-producing pregnancy. Three different scenarios were used sequentially, relating to comparisons of primary offer of IVF with three possible modalities of IUI: U-IUI, S-IUI (gonadotrophin-stimulated) and C-IUI (clomifene-stimulated). Each of the three scenarios allowed for estimation of activity and outcomes for offer of up to six IUI cycles, as per NICE guidance [1].

The EVEREST checklist for health economic studies was used as a reference to our study design (Additional File 1).

\section{Assumptions used in the model}

Assumptions used in the calculations are presented in Table 1. Evidence to populate the models was derived from peer-reviewed literature and, in the absence of such literature data, based on activity data of local subfertility unit. For estimates from the literature, we have used the excellent systematic review conducted by NICE to underpin their 2004 guidance on subfertility treatments. In addition, we have searched MEDLINE for any more recent studies on live birth rate (LBR) of S-IUI, U-IUI, and C-IUI. Relevant studies are referenced in relevant parts of the manuscript. 
Table I: Assumptions underlying the modelling and their corresponding sources

\begin{tabular}{|c|c|}
\hline Assumption & Source \\
\hline $\begin{array}{l}\text { There is an I:I ratio between "fresh" and "frozen" cycles, assuming } 25 \% \\
\text { of couples have } 0 \mathrm{FET}, 50 \% \text { have I FET and } 25 \% \text { have } 2 \text { FET }\end{array}$ & Hypothetical assumption, based on informed judgement \\
\hline IVF and IVF/ICSI ratio is I:I & Hypothetical assumption, based on informed judgement \\
\hline I00\% compliance and $0 \%$ drop out with IUI treatment & Hypothetical assumption, based on informed judgement \\
\hline \multicolumn{2}{|l|}{ Effectiveness } \\
\hline LBR following a "full" IVF (IVF/ICSI) cycle is 19.26\% (all ages) & HFEA 1995-19991 \\
\hline LBR following "frozen" IVF (IVF/ICSI) cycle is I0.40\% (all ages) & HFEA 1995-19991 \\
\hline LBR following unstimulated IUI is $3.5 \%$ per cycle & $\begin{array}{l}\text { Informed judgement, based on local data on effectiveness of stimulated } \\
\text { IUI and by halving this, peer-reviewed literature }{ }^{\prime I}\end{array}$ \\
\hline LBR following gonadotrophin-stimulated IUI is $7 \%$ per cycle & Based on local activity data \\
\hline LBR following clomifene- stimulated IUI is $3 \%$ & Informed judgement, local activity data, and peer reviewed literature 12 \\
\hline
\end{tabular}

\section{Cost}

- Cost of "fresh" IVF (IVF/ICSI) is $€ 3,214$ assuming $50 \%$ of "fresh" cycles will be ICSI cycles -Cost of "frozen" IVF (IVF/ICSI) is $£ 450$-Cost of unstimulated IUI is $\notin 449$-Cost of stimulated IUI is $£ 1005$-Cost of Clomiphene stimulated IUI is $€ 752$

$90 \%$ of couples who fail IUI proceed to IVF
NICE estimates

Hypothetical, based on informed judgement

\section{LBR: Live birth rate}

FET: Frozen embryo transfer

A cycle of IVF included a fresh cycle, and when applicable, (i.e. in couples who had additional viable embryos preserved at the time of the fresh embryo transfer, and subsequently did not achieve pregnancy through the fresh cycle) frozen embryo transfer (FET) cycles. All estimates assume a "steady state" between incident need and supply of services, and a "steady state" in progression (e.g. waiting or natural lag times) for transition to a subsequent treatment stage or strategy.

Average LBR values for fresh as well as FET IVF cycles were derived from the UK's Human Fertilisation and Embryology Authority (HFEA) population-based register 1995 to 1999 as used by NICE [1]. As supported by evidence, it was assumed that the average LBR derived from HFEA data is applicable to couples accessing IVF after previous failed IUI attempts.

Unlike IVF, there is no population-based data on the effectiveness (LBR) of S-IUI. Therefore, two sets of values for LBR were considered either based on, or informed by, data derived from the experience of a local unit, which during the period of 1993 to 2003 provided 676 cycles of S-IUI to 334 different women aged $<40$ years of age, and with a range of uptake of 1 to 5 cycles (Additional File 2) [5]. Firstly, an average LBR value for S-IUI of 7\% per cycle, independently of treatment cycle order was used. Secondly, LBR values of $10 \%, 6 \%, 4 \%, 4 \%, 2 \%$, and $2 \%$ for the $1^{\text {st }}$ to the $6^{\text {th }}$ cycle respectively were used. The first sce- nario (mean effectiveness independent of cycle order) is reasonable, as small numbers did not allow for confident calculation of LBR for subsequent to the first cycle. The second scenario reflects both the actual experience of the local unit [5], and peer-reviewed evidence [6-10], indicating decreasing effectiveness of IUI with order of cycle.

Unlike S-IUI, U-IUI has, at least up until the publication of the NICE guidelines [1] in 2004, been practiced very infrequently in the UK, therefore, there were no national or local data of relevance to U-IUI outcomes. Given this, the LBR of U-IUI was estimated to be half of that of S-IUI [11]. Similarly, the LBR for C-IUI was assumed to be 3\%, i.e. $60 \%$ lower than of S-IUI, as suggested by a Cochrane review [12].

It was assumed that on average $10 \%$ of couples who fail IUI treatment (irrespective of the number of IUI cycles received) would drop out of subfertility treatment. This was based on informed judgement, to reflect potential changes in childbearing intentions or partnership status.

\section{Cost calculations}

Costs relate to resources directly associated with fertility treatment, and exclude costs from potential complications and/or multiple pregnancy. The average costs per cycle of IVF, FET, U-IUI, and S-IUI used were the ones used in NICE's economic model [1], and were consistent with NHS costs for these treatments locally. In the absence of a 
relevant information in NICE's economic model, it was assumed that the cost of C-IUI is approximately 'half way' between cost of U-IUI and S-IUI (£752), based on local expert opinion and knowledge of drug costs.

\section{Cost-effectiveness}

The perspective used in the cost-effectiveness analysis was that of the health service. The total cost to the health service was taken as the sum of the costs of the IUI and the IVF activity generated by each scenario.

Incremental cost-effectiveness ratio (ICER) was calculated as the ratio of the difference in the combined cost of "IUI + IVF" strategies minus the cost of IVF, divided by the difference in number of live birth-producing pregnancies for each treatment strategy. In this instance ICER values therefore indicate the additional cost associated with a given treatment strategy in order to produce a single additional live birth-producing pregnancy.

\section{Sensitivity analysis}

Sensitivity analysis was undertaken to examine the robustness of the modelling and to study the impact of plausible variation in the variables for which uncertainty was judged to be higher (e.g. those least well supported by population-based data or peer-reviewed publications). Therefore, the estimates of U-IUI, S-IUI and C-IUI were varied sequentially, using different value estimates from the literature, or in the absence of alternative literature estimates, based on local experience, expert opinion, or reasonable assumptions about the plausible range of uncertainty around "best estimate" values. More specifically:

\section{- for S-IUI}

An alternative LBR estimate of $8.7 \%$ per cycle (independently of cycle order) was used based on Goverde et al [13].

\section{- for U-IUI}

An alternative LBR estimate of $4.4 \%$ per cycle (independently of cycle order) was used, assuming the LBR of U-IUI to be half of that of S-IUI [11]. In addition, LBR values of $5 \%, 3 \%, 2 \%, 2 \%, 2 \%, 2 \%$ for the $1^{\text {st }}$ to the $6^{\text {th }}$ cycle respectively were also used for U-IUI, again assuming the effectiveness of U-IUI to be half of that of S-IUI [11]. Lastly, a third estimate of an average LBR of $2 \%$ per cycle was used based on local clinical experience and expert opinion.

\section{- for C-IUI}

An alternative LBR estimate of $6.6 \%$ per cycle (independently of cycle order) was used based on reasonable assumption of having LBR of C-IUI in between LBR values of S-IUI and U-IUI. Additionally, an average LBR value of $2.5 \%$ per cycle was used, based on local experience and expert opinion.

\section{Results}

For a hypothetical cohort of 100 couples with unexplained or mild male factor subfertility, the cost of primary offer of one full cycle of IVF would be $£ 321,700$, with a cost-effectiveness ratio of $£ 12,600$ /live birth-producing pregnancy (Table 2).

\section{Cost-effectiveness of 'head-to-head' comparison of primary IUI vs. primary IVF}

Primary offer of one to six cycles of U-IUI or C-IUI, or up to three cycles of S-IUI is less costly than one cycle of fresh IVF. However, when comparing the cost-effectiveness of U-IUI, S-IUI and C-IUI to one full cycle of IVF, IVF is more cost-effective (Table 2).

\section{Cost-effectiveness of "IUI + IVF" vs. primary IVF Assuming a mean U-IUI LBR of $3.5 \%$ per cycle}

For six cycles of U-IUI the cost of IUI followed by IVF would be $£ 495,900$ with a cost-effectiveness ratio of $£ 13,100 /$ live birth-producing pregnancy (Table 2). Compared to primary offer of IVF, the ICER for offer of one to six cycles of U-IUI followed by IVF (for IUI failures) would be $£ 18,000$ to $£ 14,200$ per live birth-producing pregnancy.

\section{Assuming a mean S-IUI LBR of 7\% per cycle}

For one to six cycles of S-IUI per couple, the total cost of "IUI+IVF" would range from $£ 369,000$ to $£ 759,800$, equivalent to $£ 13,000$ to $£ 15,100$ per live birth-producing pregnancy. The ICER would increase with increase in cycle order (Table 2).

For one to six cycles of IUI, the "IUI + IVF" treatment strategy would be more costly and less cost-effective than one full cycle of IVF.

Figure 2 compares total cost and cost-effectiveness of $\mathrm{U}$ IUI to S-IUI. U-IUI is more cost-effective than S-IUI at any cycle order.

\section{Assuming a mean C-IUI LBR of $3 \%$ per cycle}

Among the three IUI modalities, C-IUI (with the lowest LBR) had the worst cost-effectiveness ratio and the worst ICER.

When assuming that LBR of IUI (any modality) was decreasing with cycle order, all above scenarios showed consistently similar results, with higher cost and worst cost-effectiveness and ICER values for "IUI+IVF" compared to IVF only.

\section{Opportunity costs}

Table 3 shows the opportunity costs, in terms of number of additional IVF cycles that could be purchased by the cost difference of IUI (followed by IVF) compared to pri- 
Table 2: Cost, outcome, cost-effectiveness ratio and incremental cost-effectiveness ratio (ICER) of providing unstimulated IUI (U-IUI), gonadotrophin stimulated IUI (S-IUI) and clomifene stimulated IUI (C-IUI) to a hypothetical cohort of couples with unexplained or male factor subfertility.

\begin{tabular}{|c|c|c|c|c|c|c|c|c|c|c|c|}
\hline \multicolumn{5}{|c|}{ U-IUI (LBR = 3.5\%) } & \multicolumn{3}{|c|}{ Full cycle of IVF } & \multicolumn{4}{|c|}{ Overall } \\
\hline $\begin{array}{c}\text { Order } \\
\text { of cycle }\end{array}$ & $\begin{array}{l}\text { No. of } \\
\text { cycles }\end{array}$ & $\begin{array}{l}\text { Live- birth } \\
\text { Deli-very } \\
\text { from IUI }\end{array}$ & Cost $t$ & $\begin{array}{c}\text { Cost/ } \\
\text { outcome } \\
\text { (t/delivery) }\end{array}$ & $\begin{array}{l}\text { No. of couples } \\
\text { having one full } \\
\text { cycle of IVF }\end{array}$ & $\begin{array}{l}\text { Live birth delivery } \\
\text { from one full cycle } \\
\text { of IVF }\end{array}$ & Cost $t$ & $\begin{array}{c}\text { Total live } \\
\text { birth delivery } \\
\text { (IUI+ IVF) }\end{array}$ & Total cost $E$ & $\begin{array}{l}\text { Total cost/total } \\
\text { outcome } \\
\text { (f/Delivery) }\end{array}$ & ICER \\
\hline \multicolumn{12}{|c|}{ U-IUI (LBR-3.5\%) } \\
\hline 0 & 0 & 0 & 0 & & 100 & 26 & 321,700 & 26 & 321,700 & 12,600 & Ref \\
\hline $\mathbf{I}$ & 100 & 4 & 44,900 & 12,800 & 87 & 22 & 279,400 & 26 & 324,300 & 12,700 & 18,600 \\
\hline 2 & 196 & 7 & 88,200 & 12,800 & 84 & 21 & 269,600 & 28 & 357,900 & 12,600 & 13,200 \\
\hline 3 & 293 & 10 & $13 \mid, 600$ & 13,000 & 81 & 21 & 260,200 & 31 & 391,800 & 12,700 & 13,400 \\
\hline 4 & 390 & 13 & 175,000 & 13,200 & 78 & 20 & 251,100 & 33 & 426,100 & 12,800 & 13,600 \\
\hline 5 & 487 & 16 & 218,500 & 13,400 & 75 & 20 & 242,300 & 36 & 460,800 & 13,000 & 13,900 \\
\hline 6 & 584 & 19 & 262,000 & 13,600 & 73 & 19 & 233,800 & 38 & 495,900 & 13,100 & 14,200 \\
\hline \multicolumn{12}{|c|}{ S-IUI (LBR = 7\%) } \\
\hline 0 & 0 & 0 & 0 & & 100 & 26 & 321,700 & 26 & 321,700 & 12,600 & Ref \\
\hline I & 100 & 7 & 100,500 & 14,400 & 84 & 21 & 269,300 & 28 & 369,800 & 13,000 & 24,000 \\
\hline 2 & 193 & 14 & 194,000 & 14,400 & 78 & 20 & 250,400 & 33 & 444,400 & 13,300 & 17,500 \\
\hline 3 & 286 & 20 & 287,900 & 14,700 & 72 & 19 & 232,900 & 38 & 520,800 & 13,700 & 16,600 \\
\hline 4 & 380 & 25 & 382,300 & 15,200 & 67 & 17 & 598,900 & 42 & 598,900 & 14,100 & 17,300 \\
\hline 5 & 475 & 30 & 477,200 & 15,700 & 63 & 16 & 678,600 & 46 & 678,600 & 14,600 & 17,800 \\
\hline 6 & 570 & 35 & 572,400 & 16,200 & 58 & 15 & 759,800 & 50 & 759,800 & 15,100 & 18,300 \\
\hline \multicolumn{12}{|c|}{ C-IUI (LBR = 3\%) } \\
\hline 0 & 0 & 0 & 0 & & 100 & 26 & 321,700 & 26 & 321,700 & 12,600 & Ref \\
\hline $\mathbf{I}$ & 100 & 3 & 75,200 & 25,100 & 87 & 22 & 280,900 & 25 & 356,000 & 14,000 & $*$ \\
\hline 2 & 197 & 6 & 148,100 & 24,700 & 85 & 21 & 272,400 & 28 & 420,600 & 15,300 & 49,400 \\
\hline 3 & 294 & 9 & 221,200 & 24,600 & 82 & 21 & 264,000 & 30 & 485,200 & 16,300 & 40,900 \\
\hline 4 & 391 & 12 & 294,200 & 24,500 & 79 & 20 & 255,600 & 32 & 549,700 & 17,200 & 38,000 \\
\hline 5 & 488 & 15 & 367,200 & 24,500 & 77 & 20 & 247,100 & 34 & 614,300 & 17,900 & 36,600 \\
\hline 6 & 585 & 18 & 440,200 & 24,500 & 74 & 19 & 238,700 & 37 & 678,900 & 18,600 & 32,500 \\
\hline
\end{tabular}

$*$ It was not possible to estimate a meaningful ICER (ICER $=(£ 356073-£ 32$ | 733$) /(25.3-25.6)=-£|| 4,467 /$ Live birth-producing pregnancy as compared to full cycle of IVF).

Cost/unit; IVF $=€ 3,2|4, U-| \mathrm{UI}=€ 449, \mathrm{~S}-\mathrm{IUI}=£ \mid, 005, \mathrm{C}-\mathrm{IUI}=£ 752 \mathrm{Live}$ birth delivery refers to live birth- producing pregnancyFigures are rounded to the nearest hundred 


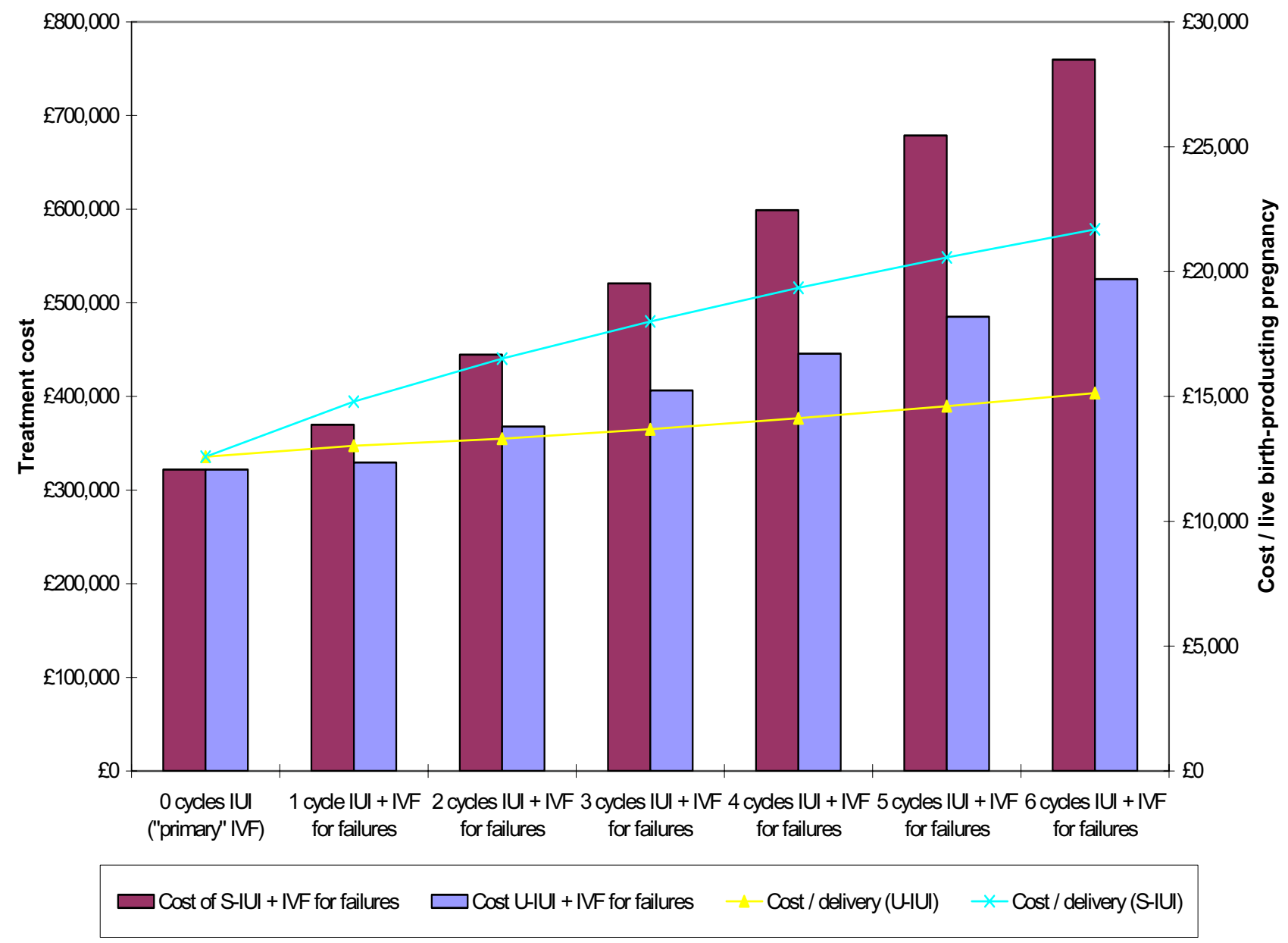

Figure 2

Cost and cost-effectiveness (per live birth-producing pregnancy) of different uptake of IUI and S-IUI among a hypothetical cohort of 100 couples eligible for both IUI and IVF. Assumes constant LBR of $7 \%$ and $3.5 \%$ for S-IUI and IUI.

mary offer of IVF alone. Providing six cycles of U-IUI and one full cycle of IVF to $90 \%$ of couples who failed IUI, would increase subfertility related health care expenditure by $£ 174,200$. If this amount was allocated for purchasing of IVF, then an additional 54 couples would have access to IVF and an additional 14 couples would achieve a live birth-producing pregnancy. If six cycles of S-IUI were offered instead of U-IUI, the otherwise avoidable cost to the health care system would be an additional $£ 438,000$, sufficient to otherwise fund 136 IVF cycles, and to enable additional 35 couples to achieve live birth. If a smaller number of IUI cycles is offered the opportunity costs would be minimised, but the net difference would always be in favour of the primary IVF strategy.

\section{Sensitivity analysis}

After considering different plausible LBR values for S-IUI, U-IUI and C-IUI, the primary offer of IVF remained more cost-effective than providing "IUI+IVF" (Table 4) and associated with less opportunity cost (Table 5).

\section{Discussion}

The findings suggest that for couples with unexplained or mild male factor subfertility, primary offer of a full IVF cycle is less costly and more cost-effective than primary offer of any IUI modality followed by IVF (for IUI failures). Importantly, the cost of primary IUI (any modality) increases and its cost-effectiveness decreases with increasing number of IUI cycles offered. Between S-IUI and UIUI, S-IUI followed by IVF was associated with higher cost and lower cost-effectiveness compared with U-IUI followed by IVF. The sensitivity analysis findings indicate 
Table 3: Cost difference, number of additional full cycles of IVF that could be purchased and corresponding additional number of live birth-producing pregnancies by the estimated cost difference of providing "IUI+IVF" compared to primary offer of IVF

\begin{tabular}{|c|c|c|c|c|c|c|}
\hline \multirow[b]{2}{*}{ IUI modality } & \multicolumn{6}{|c|}{ "IUI + IVF" for those failing IUI } \\
\hline & $\begin{array}{l}\text { One cycle } \\
\text { of IUI }\end{array}$ & $\begin{array}{l}\text { Two cycles } \\
\text { of IUI }\end{array}$ & $\begin{array}{l}\text { Three cycles } \\
\text { of IUI }\end{array}$ & $\begin{array}{l}\text { Four cycles } \\
\text { of IUI }\end{array}$ & $\begin{array}{l}\text { Five cycles } \\
\text { of IUI }\end{array}$ & $\begin{array}{l}\text { Six cycles } \\
\text { of IUI }\end{array}$ \\
\hline \multicolumn{7}{|l|}{ U-IUI (LBR = 3.5\%) } \\
\hline Cost difference "IUI+IVF" vs. primary IVF & $£ 2,600$ & $£ 36,100$ & $£ 70,100$ & $£ 104,400$ & $E 139,100$ & $£ \mid 74,200$ \\
\hline $\begin{array}{l}N^{\circ} \text { of IVF cycles that would be purchased by the } \\
\text { cost difference }\end{array}$ & 1 & II & 22 & 32 & 43 & 54 \\
\hline $\begin{array}{l}\text { No of live birth-producing pregnancies expected } \\
\text { from IVF cycles that would have been purchased by } \\
\text { the cost difference }\end{array}$ & 0 & 4 & 6 & 8 & 11 & 14 \\
\hline \multicolumn{7}{|l|}{ S-IUI (LBR = 7\%) } \\
\hline Cost difference "IUI+IVF" vs. primary IVF & $£ 48,100$ & $£ 122,600$ & $£ 199,100$ & $£ 277,200$ & $€ 356,900$ & $£ 438,000$ \\
\hline $\begin{array}{l}\text { No of IVF cycles that would be purchased by the } \\
\text { cost difference }\end{array}$ & 15 & 38 & 62 & 86 & 111 & 136 \\
\hline $\begin{array}{l}\text { No of live birth-producing pregnancies expected } \\
\text { from IVF cycles that would have been purchased by } \\
\text { the cost difference }\end{array}$ & 4 & 10 & 16 & 22 & 28 & 35 \\
\hline \multicolumn{7}{|l|}{ C-IUI (LBR = 3\%) } \\
\hline Cost difference "IUI+IVF" vs. primary IVF & $£ 34,300$ & $£ 98,900$ & $£ 163,400$ & $£ 228,000$ & $£ 292,600$ & $£ 357,200$ \\
\hline $\begin{array}{l}\text { No of IVF cycles that would be purchased by the } \\
\text { cost difference }\end{array}$ & 11 & 31 & 51 & 71 & 91 & 111 \\
\hline $\begin{array}{l}\text { No of live birth-producing pregnancies expected } \\
\text { from IVF cycles that would have been purchased by } \\
\text { the cost difference }\end{array}$ & 3 & 8 & 13 & 18 & 23 & 28 \\
\hline
\end{tabular}

Figures are rounded to the nearest hundred.

that the main finding of inferior cost-effectiveness of the primary IUI, compared with primary IVF, is robust. A previous study on cost impact implications of the 2004 NICE guidance has failed to reach similar conclusions, as it did not accurately simulate real life patient experience and clinical management [1].

In principle, a prospective randomised controlled trial would have been a superior study design to answer this study's research question. However, such a study would have had to entertain certain practical obstacles, including ethical clearance, and may not be forthcoming for many years to come. At the same time resource allocation and service development policy decisions have to be made currently and in the near future. In the absence of RCTbased evidence, mathematical modelling synthesising evidence from various high quality sources is the only rational way to support health care policy decision-making [14].

Published data comparing the cost-effectiveness of IVF versus IUI are scarce. Some studies indicate that IUI may be more cost-effective than IVF in cases of unexplained and moderate male subfertility [13,15-17]. However, these studies have not accounted for the potential subsequent FET component of IVF strategies, which increases their cost-effectiveness [17]. More importantly, these studies do not take into account the potential for eventual "transfer" of most couples who fail IUI to IVF, a crucial consideration by commissioners of healthcare services when both IUI and IVF are funded from the same budget (as is the case in the UK NHS).

The majority of the literature on IUI effectiveness comes from uncontrolled retrospective case series and cohort designs, could overestimate treatment effectiveness because of selection bias and consideration of clinical pregnancy as opposed to live birth as the study outcome. Also, the number of abandoned cycles is generally excluded from the denominator, leading to inflated estimates of effect [11]. A further problem is that the reported effectiveness of IUI is very variable, ranging from small integer numbers to up to over $30 \%$. This heterogeneity may be due to factors including differences in study populations, ovarian stimulation regimes, the number of inseminations per cycle, the timing of insemination, and 
Table 4: Sensitivity analysis estimates of incremental cost-effectiveness ratios (ICER) of providing "IUI+IVF" compared to primary offer of IVF, varied sequentially.

\begin{tabular}{|c|c|c|c|c|c|c|c|}
\hline \multirow[t]{2}{*}{ Varied variables } & \multirow[t]{2}{*}{ Source of assumption } & \multicolumn{6}{|c|}{ ICER ( $E$ /live birth-producing pregnancy) } \\
\hline & & $\begin{array}{l}\text { I cycle } \\
\text { of IUI }\end{array}$ & $\begin{array}{l}2 \text { cycles } \\
\text { of IUI }\end{array}$ & $\begin{array}{l}3 \text { cycles } \\
\text { of IUI }\end{array}$ & $\begin{array}{l}4 \text { cycles } \\
\text { of IUI }\end{array}$ & $\begin{array}{l}5 \text { cycles } \\
\text { of IUI }\end{array}$ & $\begin{array}{l}6 \text { cycles } \\
\text { of IUI }\end{array}$ \\
\hline \multicolumn{8}{|l|}{ S-IUI } \\
\hline $\mathrm{LBR}=8.7 \%$ & Goverde et al ${ }^{13}$ & $£ 10,400$ & $£ 10,900$ & $£ \mid 1,600$ & $£ 12,300$ & $E 13,000$ & $£ \mid 3,800$ \\
\hline LBR varying by cycle order* & $\begin{array}{l}\text { Local unit's experience and peer-reviewed } \\
\text { literature } 6-10\end{array}$ & $£ 7,700$ & $£ \mid 2,300$ & $£ \mid 6,800$ & $£ \mid 9,900$ & $£ 24,300$ & $£ 28,300$ \\
\hline \multicolumn{8}{|l|}{ U-IUI } \\
\hline $\mathrm{LBR}=4.4 \%$ & LBR of U-IUI as half of that of S-IUI'I & $€ 0$ & $£ 7,500$ & $£ 8,700$ & $£ 9,300$ & $£ 9,800$ & $£ \mid 0,200$ \\
\hline $\mathrm{LBR}=2 \%$ & Local experience and expert opinion & \} $&{£ 91,700} &{£ 42,400} &{£ 35,700} &{£ 33,300} &{£ 32,100} \\
{\hline \text { LBR varying by cycle order } \pm} &{\text { LBR of U-IUI as half of that of S-IUI'I }} &{£ 4 I, 600} &{£ 40,400} &{£ 47,600} &{£ 51,900} &{£ 54,900} &{£ 57,100} \\
{\hline \multicolumn{8}{|l|}{\text { C-IUI }}\text { C-IUI }} \\
{\hline \text { LBR }=6.6 \%} &{\begin{array}{l}\text { Reasonable assumption, LBR of C-IUI } \\
\text { between the values of LBR of } U \text {-IUI and S-IUI }\end{array}} &{£ 9,500} &{£ 10,500} &{£ 10,700} &{€ 10,800} &{£ 10,900} &{£ 10,900} \\
{\hline \mathrm{LBR}=2.5 \%} &{\text { Local experience and expert opinion }} &{\text { ף }} &{£ 81,900} &{£ 53,900} &{£ 46,900} &{£ 43,700} &{£ 41,900} \\
$\hline
\end{tabular}

* LBR of S-IUI of $10 \%, 6 \%, 4 \%, 4 \%, 2 \%, 2 \%$ for cycles I to 6 respectively

\pm LBR of U-IUI of $5 \%, 3 \%, 2 \% 2 \%, 2 \%, 2 \%$ for cycles I to 6 respectively.

TIt was not possible to estimate a meaningful ICER because of very small denominator in case of one cycle of U-IUI (when LBR $=2 \%)$ and one cycle of C-IUI (when LBR $=2.5 \%$ ) as compared to I full cycle of IVF.

ICER was estimated based on cost and effectiveness of "IUI+IVF" compared to full cycle of IVF.

Figures are rounded to the nearest hundred

methods of sperm preparation [18]. Also, the reported trials involved an exceedingly small fraction of the very great number of patients world-wide undergoing treatment, so generalisations have to be cautious [19]. Given the above limitations of published evidence, we used local IUI activity data as the main source of our data in relation to the effectiveness of IUI, but complemented those with different sets of estimates in sensitivity analysis. The results obtained using local current data could better reflect the likely current UK practice in a "real life" situation, and for an unselected population.

We used a mean LBR value of 7\% for S-IUI based on local experience on 676 cycles of S-IUI over 10 years. In most studies the pregnancy rate per cycle of S-IUI is approximately $10 \%$ [20-22]. A prospective randomised study from The Netherlands showed that the average LBR of SIUI of $8.7 \%$ per cycle [13]. NICE in its economic model has used results of an RCT from the US [23] reporting cumulative pregnancy rates of $33 \%$ for S-IUI for an average of 5.6 cycles. In our model, if the cumulative LBR for five and six cycles of S-IUI is considered, it equates to $30 \%$ and 35\% respectively, and as such our assumptions are comparable to the order of the estimates used by NICE.
The effectiveness (LBR) of IUI was judged to be 3.5\% per treatment cycle -this represents an informed judgement, based on the literature. Many experts would support that this is actually a high estimate, but we preferred to use a "generous" estimate. If the true estimate is lower, any bias introduced from this assumption would have favoured the cost-effectiveness of U-IUI, and would have made IVF less cost effective, i.e. if a lower LBR value for U-IUI was used, the results would have been even more favourable for primary offer of IVF as the preferred treatment strategy.

We used average success rates rather than age- and indication-specific LBRs. Maternal age affects outcomes of IUI, but so does for IVF [1]. Similarly, different subfertility indications are associated with different success rates for IUI, but again the same is true for IVF. Therefore, the lack of stratification (by age or indication) is very unlikely to influences the results for either modality. In any case, the hypothetical cohort of 100 couples can be assumed to have an identical case mix in terms of age and indication stratification, whichever treatment strategy is offered.

The modelling of costs has concentrated on the nominal cost of IVF and IUI. Other essential aspects of the service 
Table 5: Sensitivity analysis estimates of cost difference, and the additional number of live birth-producing pregnancies by the estimated cost difference of providing "IUI+IVF" compared to primary offer of IVF, varied sequentially.

\begin{tabular}{|c|c|c|c|c|c|c|}
\hline \multirow{2}{*}{$\begin{array}{l}\text { Variable varied } \\
\text { S-IUI }\end{array}$} & \multicolumn{6}{|c|}{ Cost difference $f$ [("IUI+IVF") - IVF] } \\
\hline & I cycle of IUI & 2 cycles of IUI & 3 cycles of IUI & 4 cycles of IUI & 5 cycles of IUI & 6 cycles of IUI \\
\hline $\mathrm{LBR}=8.7 \%$ & $£ 43,100$ & $E \mid I I, 900$ & $£ \mid 83,400$ & $£ 257,400$ & $£ 333,800$ & $£ 4 \mid 2,200$ \\
\hline LBR varying by cycle order* & $£ 39,400$ & $E \mid 14,200$ & $E 199,500$ & $£ 287,200$ & $£ 379,900$ & $£ 474,400$ \\
\hline \multicolumn{7}{|l|}{ U-IUI } \\
\hline $\mathrm{LBR}=4.4 \%$ & to & $£ 30,700$ & $£ 62,100$ & $£ 94,100$ & $E \mid 26,600$ & $E \mid 59,700$ \\
\hline $\mathrm{LBR}=2 \%$ & $£ 6,900$ & $£ 45,300$ & $£ 83,700$ & $E \mid 22,300$ & $E|6|, 000$ & $£ 199,900$ \\
\hline LBR varying by cycle order \pm & $£ 53,800$ & $£|4|, 100$ & $£ 233,400$ & $£ 326,800$ & $£ 420,300$ & $£ 514,000$ \\
\hline \multicolumn{7}{|l|}{ C-IUI } \\
\hline LBR $=6.6 \%$ & $£ 23,900$ & $£ 76,300$ & $£ 128,900$ & $£ \mid 81,600$ & $£ 234,200$ & $£ 286,800$ \\
\hline LBR $=2.5 \%$ & $£ 35,800$ & $£ 102,100$ & $£ \mid 68,400$ & $£ 234,700$ & $£ 301,000$ & $£ 367,300$ \\
\hline
\end{tabular}

No. of live births expected from full cycles of IVF that could be purchased by the estimated cost difference

\section{S-IUI}

\begin{tabular}{lllllll}
\hline LBR $=8.7 \%$ & 3 & 9 & 15 & 20 & 27 & 33 \\
LBR varying by cycle order* & 3 & 9 & 16 & 23 & 30 & 38
\end{tabular}

\section{U-IUI}

\begin{tabular}{lcccccc}
\hline LBR $=4.4 \%$ & 0 & 2 & 5 & 7 & 10 & 13 \\
LBR $=2 \%$ & 1 & 4 & 7 & 10 & 13 & 16 \\
LBR varying by cycle ordert & 4 & 11 & 19 & 26 & 33 & 41
\end{tabular}

\section{C-IUI}

\begin{tabular}{lllllll}
\hline LBR $=6.6 \%$ & 2 & 6 & 10 & 14 & 19 & 23 \\
LBR $=2.5 \%$ & 3 & 8 & 13 & 19 & 24 & 29 \\
\hline
\end{tabular}

* LBR of S-IUI of $10 \%, 6 \%, 4 \%, 4 \%, 2 \%, 2 \%$ for cycles I to 6 respectively \pm LBR of U-IUI of $5 \%, 3 \%, 2 \% 2 \%, 2 \%, 2 \%$ for cycles I to 6 respectively.

Figures of cost differences are rounded to the nearest hundred.

(e.g. diagnostic activity, incident and follow-up appointments, counselling) have not been calculated, because they were assumed to be already occurring (i.e. requiring no 'new' money) and to be similar to both treatment strategies. The cost associated with complications, such as multiple gestation and birth, were also not included in calculations. Evidence suggests that there is no statistically significant difference in the incidence of ovarian hyperstimulation syndrome (OHSS) and multiple pregnancy rate between S-IUI and IVF [13]. As such, it is unlikely that inclusion of the costs of complications would have had an impact on the comparative cost-effectiveness of S-IUI and IVF.

Lastly, anecdotally, undergoing IUI followed by IVF may be more psychologically distressing to the couple compared to IVF alone, as it may be more frustrating to have, on average, comparatively more failed treatment cycles although direct evidence about this assumption is lacking. However, some patients may have a positive preference for IUI or an aversion for IVF (on philosophical, or religious grounds). We acknowledge that traditional meth- 
ods of cost-effectiveness analysis like the ones used in this study, are not useful tools when dealing with philosophically-grounded patient preferences - which however are exceptional, rather than the norm.

\section{Conclusion}

Our study indicates that for couples with unexplained or mild male factor subfertility, a primary treatment offer of any modality of IUI instead of primary offer of IVF is costineffective, and therefore associated with considerable opportunity costs. The additional and avoidable costs incurred put pressure on the health care system to cope with extra demand and activity for a treatment of low effectiveness, making the wider availability of the most effective treatment (IVF) more difficult, and thus disadvantaging couples who could have otherwise benefited from it.

\section{Competing interests}

The author(s) declare that they have no competing interests.

\section{Authors' contributions}

GL and NP constructed the mathematical model, reviewed the literature on estimates of treatment effectiveness, and inputted data into the model. RM collected and provided original data on IUI effectiveness used in the model and helped with literature search and interpretation. All authors contributed to the writing of the manuscript. GL is the guarantor.

\section{Additional material}

\section{Additional File 1}

EVEREST Statement: Checklist for health economics paper. EVEREST checklist for health economics studies with respect to this study design, data collection, and analysis and interpretation of the results Click here for file

[http://www.biomedcentral.com/content/supplementary/14726963-6-80-S1.doc]

\section{Additional File 2}

Local data on outcome of 676 cycles of S-IUI in 334 couples with unexplained infertility women aged $<40$ years. Results of local data on S-IUI uptake and outcome, live birth-producing pregnancy, by treatment cycle order.

Click here for file

[http://www.biomedcentral.com/content/supplementary/14726963-6-80-S2.doc]

\section{Acknowledgements}

We would like to thank our health economist colleagues Mr Ed Wilson, $\mathrm{Dr}$ Jon Sussex and Professor Ceri Phillips for helpful comments in earlier version of the manuscript. We also thank all members of the Norfolk, Suffolk and Cambridgeshire Subfertility Services Advisory Group, for helpful dis- cussions of aspects of this work presented to the Group and for providing the key operational stimulus for the work.

\section{References}

I. National Collaborating Centre for Women's Children's Health: Fertility: assessment and treatment for people with fertility problems. Clinical Guideline London: RCOG Press; 2004.

2. NICE: CGOII Fertility-costing for clinical guidelines: England London: SECTA Partners for Change; 2004.

3. Hensher M, Fulop N, Coast J, Jefferys E: The hospital of the future: Better out than in? Alternatives to acute hospital care. BMJ 1999, 3 1 9: I | 27-30.

4. Royere $D$ : Intrauterine insemination in human: state-of-theart. Gynecol Obstet Fertil 2004, 32(1 90):873-9.

5. Mathur R: IUI after NICE - a role for cautious ovarian stimulation? Human Fertility 2005, 8: I26. [abstract]

6. Nuojua-Huttunen S, Tomas C, Bloigu R, Tuomivaara L, Martikainen H: Intrauterine insemination treatment in subfertility: an analysis of factors affecting outcome. Hum Reprod 1999, 14(3):698-703.

7. Burr RW, Siegberg R, Flaherty SP, Wang XJ, Mathews CD: The influence of sperm morphology and the number of motile sperm inseminated on the outcome of intrauterine insemination combined with mild ovarian stimulation. Fertil Steril 1996, 65: $127-32$.

8. Tomlinson MJ, Amissah-Arthur JB, Thompson KA, Kasraie JL, Bentick $B$ : Prognostic indicators for intrauterine insemination (IUI): statistical model for IUI success. Hum Reprod 1996, I I: I 892-6.

9. Aboulghar M, Mansour R, Serour G, Abdrazek A, Amin Y, Rhodes C: Controlled ovarian hyperstimulation and intrauterine insemination for treatment of unexplained infertility should be limited to a maximum of three trials. Fertil Steril 2000, 75(I):88-9.

10. Dodson WC, Haney AF: Controlled ovarian hyperstimulation and intrauterine insemination for treatment of infertility. Fertil Steril 199I, 55(3):457-67.

II. Hughes EG: The effectiveness of ovulation induction and intrauterine insemination in the treatment of persistent infertility: a meta-analysis. Hum Reprod 1997, I 2: 1865-72.

12. Athaullah N, Proctor M, Johnson NP: Oral versus injectable ovulation induction agents for unexplained subfertility (Review). The Cochrane Library 2002.

13. Goverde AJ, McDonnell J, Vermeiden JP, Schats R, Rutten FF, Schoemaker J: Intrauterine insemination or in-vitro fertilisation in idiopathic subfertility and male subfertility: A randomised trial and cost-effectiveness analysis. Lancet 2000, 355: I3-8.

14. Capewell S, Critchley JA: Why model coronary heart disease? Eur Heart J 2002, 23: I I0-I I6.

15. Karande VC, Korn A, Morris R, Rao R, Balin M, Rinehart J, Dohn K, Gleicher N: Prospective randomised trial comparing the outcome and cost of in vitro fertilisation with that of a traditional treatment algorithm as first-line therapy for couples with infertility. Fertil Steril 1999, $71: 468-75$.

16. Philips Z, Barraza-Llorens M, Posnett J: Evaluation of the relative cost-effectiveness of treatments for infertility in the UK. Hum Reprod 2000, 15:95-106.

17. Van Voorhis BJ, Stovall DW, Allen BD, Syrop CH: Cost-effective treatment of the infertile couple. Fertil Steril 1998, 70:995-I005.

18. Ombelet W: IUI and evidence-based medicine: an urgent need for translation into our clinical practice. Gynecol Obstet Invest 2004, 59: I-2.

19. Collins J: Stimulated intrauterine insemination is not a natural choice for the treatment of unexplained subfertility Current best evidence for the advanced treatment of unexplained subfertility. Hum Reprod 2003, 18(5):907-12.

20. Isaksson R, Tiitinen A: Superovulation combined with insemination or intercourse in the treatment of couples with unexplained infertility and minimal endometriosis. Acta Obstet Gynecol Scand 1997, 76:550-4.

21. Sahakyan M, Harlow BL, Hornstein MD: Influence of age, diagnosis, and cycle number on pregnancy rates with gonadotropininduced controlled ovarian hyperstimulation and intrauterine insemination. Fertil Steril 1999, 72:500-4.

22. Van der Westerlaken LA, Naaktgeboren N, Helmerhorst FM: Evaluation of pregnancy rates after intrauterine insemination 
according to indication, age, and sperm parameters. J Assist Reprod Genet 1998, 15:359-64.

23. Guzick DS, Sullivan MW, Adamson GD, Cedars MI, Falk RJ, Peterson EP, Steinkampf MP: Efficacy of treatment for unexplained infertility. Fertil Steril 1998, 70:207-13.

\section{Pre-publication history}

The pre-publication history for this paper can be accessed here:

http://www.biomedcentral.com/1472-6963/6/80/prepub

Publish with Bio Med Central and every scientist can read your work free of charge

"BioMed Central will be the most significant development for disseminating the results of biomedical research in our lifetime. " Sir Paul Nurse, Cancer Research UK

Your research papers will be:

- available free of charge to the entire biomedical community

- peer reviewed and published immediately upon acceptance

- cited in PubMed and archived on PubMed Central

- yours - you keep the copyright
BioMedcentral 